\title{
The MRI Findings of the Right-Sided Fetal Lung Can Be Used to Predict Postnatal Mortality and the Requirement for Extracorporeal Membrane Oxygenation in Isolated Left-Sided Congenital Diaphragmatic Hernia
}

\author{
MASAHIRO HAYAKAWA, TAKAHIKO SEO, ATSUO ITAKUA, SEIJI HAYASHI, MEGUMI MIYAUCHI, YOSHIAKI SATO, \\ AKIKO SAITO, ATSUSHI NAKAYAMA, KOJI TAKEMOTO, MASAYUKI HASEGAWA, KENITIRO KANEKO, MAYUMI OKADA, \\ HIROMI HAYAKAWA, SEIJI SUMIGAMA, FUMITAKA KIKKAWA, HISAMI ANDO, AND SEIJI KOJIMA

\begin{abstract}
Maternity and Perinatal Care Center [M.H., A.I., K.T., M.H., M.O., F.K.], Nagoya University Hospital, Nagoya, Aichi-prefecture, 466-8550 Japan; Department of Pediatric Surgery [T.S., K.K., H.A.], Department of Pediatrics [S.H., M.M., Y.S., A.S., A.N., S.K.], 466-8550 Japan; Department of Obstetrics and Gynaecology [A.I.], Faculty of Medicine, Saitama Medical University, Moroyama,
\end{abstract} \\ Department of Obstetrics and Gynecology [H.H., S.S., F.K.], Graduate School of Medicine, Nagoya University, Nagoya, Aichi-prefecture, \\ Saitama-prefecture, 350-0495 Japan
}

\begin{abstract}
We evaluated whether a correlation existed between fetal pulmonary magnetic resonance imaging (MRI) findings and postnatal mortality, as well as the requirements for extracorporeal membrane oxygenation (ECMO) in infants with prenatally diagnosed, isolated left-sided congenital diaphragmatic hernia (CDH). Twenty-one pregnant women carrying fetuses with $\mathrm{CDH}$ underwent 30 MRI scans, and the right-sided fetal lung volume (FLV) was measured. In the control, a regression analysis was performed to associate FLV with gestational age. This yielded a formula that enabled the calculation of the expected right fetal lung volume (ERFLV). In cases with CDH, the right-sided observed FLV/ERFLV $(=\%$ RFLV) was compared with both the postnatal mortality and whether ECMO was required. Additionally, we investigated the relationship between the lung shape on MRI (whether there was a complete pulmonary baseline present) and postnatal mortality. The $\%$ RFLV was significantly lower in nonsurvivors compared with survivors. Among survivors, the \%RFL was significantly lower in infants who required ECMO compared with those who did not. The pulmonary baseline was completely present in $3(38 \%)$ and 13 $(100 \%)$ of the nonsurvivors and survivors, respectively. In isolated left-sided $\mathrm{CDH}$, the \% RFLV is a good predictor not only of postnatal mortality but also of the requirement for ECMO. (Pediatr Res 62: 93-97, 2007)
\end{abstract}

$\mathrm{T}$ The incidence of CDH is 1 case per 2000-3800 live births (1-4). This anomaly is associated with significant morbidity and mortality rates. During the past decade, new strategies for managing $\mathrm{CDH}$, including HFO (5-7), INO (8), and ECMO $(5,9,10)$ have improved overall survival. Despite these advances, the survival rate of cases diagnosed prenatally remains low $(4,11)$.

The degree of pulmonary hypoplasia and the presence of intractable PPHN are the two most important determinants of mortality (12). The severity of pulmonary hypoplasia varies

Received September 21, 2006; accepted February 19, 2007.

Correspondence: Masahiro Hayakawa, M.D., Ph.D., Maternity and Perinatal Care Center, Nagoya University Hospital, 65 Tsurumai-cho, Showa-ku Nagoya, 466-8550 Japan; e-mail: masahaya@med.nagoya-u.ac.jp over a wide range. Thus, measuring the degree of pulmonary hypoplasia prenatally may determine prognosis. Pulmonary hypoplasia is most frequently evaluated with ultrasound. The presence of polyhydramnios (13), mediastinal shift (14), and liver herniation (15), all of which are markers of pulmonary hypoplasia, may be used to predict prognosis. Additionally, the residual lung area, as estimated by ultrasonography, is also used to predict survival.

MRI is another imaging modality that has increasingly become popular for prenatal diagnosis. There are a few studies that describe measuring FLV with MRI (16-18). In two of these studies, the FLV was a good predictor of postnatal mortality due to pulmonary hypoplasia $(17,18)$. However, neither of these studies addressed how this predictive information could affect management of the infant in the NICU. The purpose of this study was to determine whether the right-sided FLV was a useful predictor of neonatal outcome in infants with isolated left-sided $\mathrm{CDH}$. We investigated whether a correlation existed between the results of antenatal evaluation and how the infant was managed in the NICU. Finally, we investigated whether the shape of the fetal right lung was a predictor of postnatal mortality.

\section{PATIENTS AND METHODS}

This prospective study was conducted between July 1997 and June 2006 in the Maternity and Perinatal Care Center, Nagoya University Hospital. This study was approved by the Institutional Review Board of Nagoya University Hospital. All parents provided informed consent.

Thirty-four neonates with $\mathrm{CDH}$ were admitted by our hospital. Six of these cases were diagnosed postnatally and transferred to our hospital. Twentyeight cases were diagnosed prenatally with ultrasonography. The median

Abbreviations: CDH, congenital diaphragmatic hernia; ECMO, extracorporeal membrane oxygen; ERFLV, expected right fetal lung volume; FETO, fetal endoscopic tracheal occlusion; FLV, fetal lung volume; HFO, highfrequency oscillation ventilation; INO, inhaled nitric oxide; NPV, negative predictive value; $\% \mathbf{R F L V}$, the ratio of observed right-sided fetal lung volume to the expected right-sided fetal lung volume; PPHN, persistent pulmonary hypertension of newborn; PPV, positive predictive value 
(range) gestational age of ultrasonographic diagnosis was 29 (19-37) weeks of gestation. The exclusion criteria were infants with other congenital anomalies, multiple gestations, and preterm birth. Three infants had congenital anomalies (Cornelia de Lange Syndrome, 1; karyotype anomaly, 1; multiple anomalies; 1). Two were preterm infants. One pregnant woman was transferred to another hospital before delivery. MRI scans were obtained once or twice in 18 and 9 pregnant women, respectively. One MRI scan was not available for adequate analysis. Therefore, we evaluated the 30 MRI scans of the remaining 21 fetuses. The median gestational age at MRI was 35.4 (25.9-37.8) weeks. All of the 21 cases had isolated left-sided CDH.

MRI studies were performed with a 1.5-T system (Visart EX 1.5T, Toshiba, Tokyo, Japan). T2-weighted images were obtained by a single-shot rapid acquisition and relaxation enhancement sequence with a repetition time of 6,000-10,000 ms, and an effective echo time of $120 \mathrm{~ms}$. Section thickness and the intersection gap were 7.0-10.0 and 1.4-2.0 mm, respectively. T2weighted images were obtained in the transverse and coronal planes. The cross-sectional area of the right lung was manually outlined and a computergenerated area was obtained. The area was multiplied by the combination of the section thickness and the intersection gap to calculate the volume for that section. The total right lung volume was obtained by adding the volumes of each section. The final right FLV was obtained by averaging the volumes measured on the transverse and coronal images.

The control group consisted of 24 infants without thoracic abnormalities. Their indications for MRI were as follows: placental abnormalities (placenta previa; 8 , adhesion of the placenta; 2 , hydatidiform mole coexisting with a live twin fetus; 1), fetal abnormalities (hydrocephalus; 3 , agenesis of the corpus callosum; 1 , cerebellar hypoplasia; 1 , cystic hygroma; 1 , gastroschisis; 1, ovarian tumor; 2, multicystic dysplastic kidney; 2, spina bifida; 2). MRI obtained from the control group was performed between 23.4 and $37.9 \mathrm{wk}$ of gestation. In the control group, a regression analysis was preformed to associate right FLV with gestational age (GA). The regression analysis yielded the following formula: ERFLV $(\mathrm{mL})=0.003 \times \mathrm{GA}^{2.707}(p<$ 0.0001 ) (Fig. 1). The interobserver and intraobserver variability was $5 \%$ and $5 \%$, respectively.

In the cases with $\mathrm{CDH}$, we calculated the relative right-sided lung volume (\%RFLV), defined as the ratio of the observed right FLV to the ERFLV, to quantify the degree of pulmonary hypoplasia.

In severe $\mathrm{CDH}$, the mediastinum usually shifts to compress the contralateral lung. The compression is most pronounced in the lower lobe. In this situation, the pulmonary baseline cannot be fully visualized with MRI. We defined this phenomenon as "the incomplete pulmonary baseline." We evaluated whether the right-sided pulmonary baseline presented completely or not (Fig. 2). MRI images with a complete baseline on at least one section were considered to have a complete pulmonary baseline. Those with no complete baselines in any sections were referred to as having an incomplete pulmonary baseline.

Polyhydramnios was defined as an amniotic fluid index of more than 25 (19). Preterm labor was defined as regular uterine contractions with documented cervical dilatation and effacement before $37 \mathrm{wk}$. In our institution, $\mathrm{CDH}$ and its management were thoroughly explained to the parents, who then chose their preferred mode of delivery. When maternal or fetal conditions

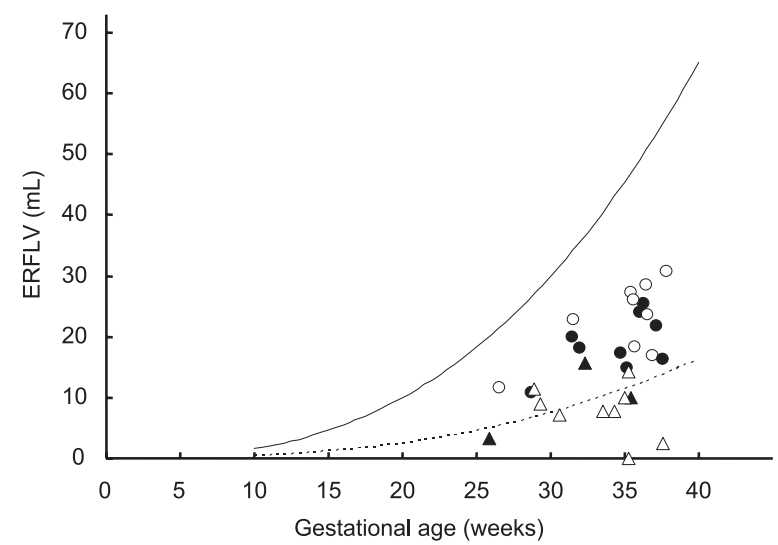

Figure 1. RFLV measured by MRI as a function of gestational age. The solid line corresponds to the expected fetal lung volume at each gestational age. The dotted line corresponds to $25 \%$ of the expected fetal lung volume. Open triangles $(\triangle)$ indicate nonsurvivors without ECMO. Closed triangle $(\mathbf{\Delta})$ indicate nonsurvivors with ECMO. Open circles $(O)$ indicate survivors without ECMO. Closed circles $(\bullet)$ indicate survivors with ECMO.
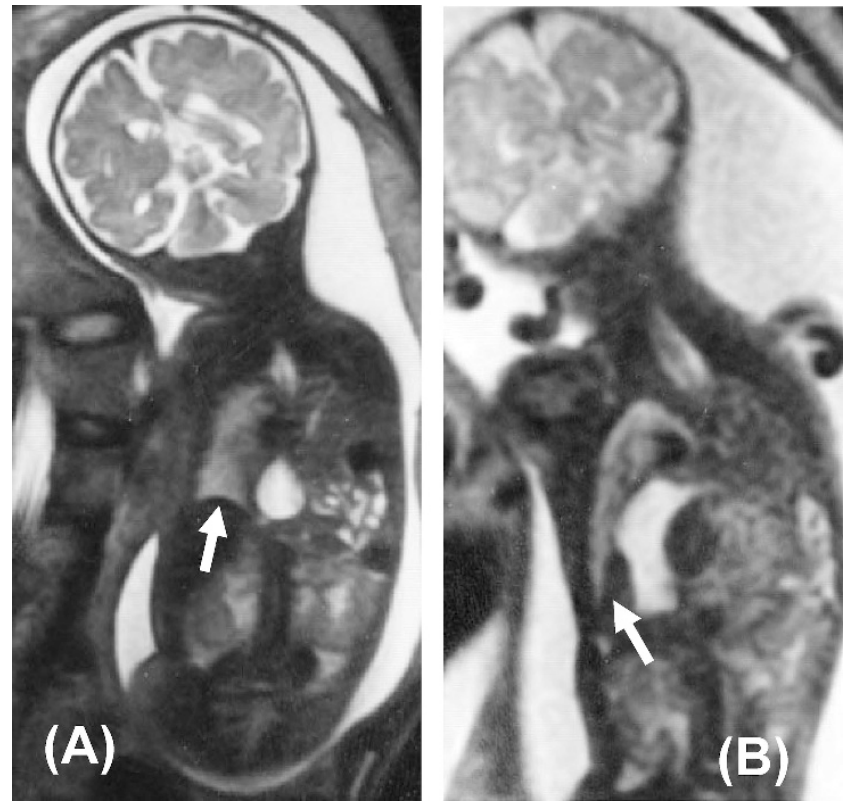

Figure 2. The shape of the contralateral pulmonary baseline on fetal MRI. Arrows indicate the pulmonary baseline. (A) Complete contralateral pulmonary baseline; $(B)$ incomplete contralateral pulmonary baseline.

precluded vaginal delivery, a cesarean section was performed. The infants were intubated immediately after birth and mechanically ventilated with HFO. All infants were sedated. Pulmonary artery pressure and ductal shunting were repeatedly evaluated using echocardiography (SONOS 5500, Philips, Tokyo, Japan). Pre- and postductal oxygen saturations $\left(\mathrm{SpO}_{2}\right)$ were recorded continuously. When a discrepancy between the pre- and postductal $\mathrm{SpO}_{2}$ was recognized, an echocardiography was performed to test for PPHN. Once a diagnosis of PPHN had been confirmed, therapy with INO commenced. ECMO was used for intractable cases of PPHN that failed to respond to INO. In our hospital, the criteria for initiating ECMO were as follows: a preductal $\mathrm{AaDO}_{2}$ of more than 600 and/or a preductal oxygen index of more than 40 , in spite of the infant received INO. Aggressive therapy was withdrawn from some infants with very severe pulmonary hypoplasia. Surgical repair was only performed once the infant's condition was completely stabilized.

We compared the \%RFLV between nonsurvivors and survivors. A receiver operative characteristics (ROC) curve was generated to determine the threshold of the \%RFLV to predict postnatal mortality. We also evaluated the relationship between mortality and whether the right-sided pulmonary baseline was completely present. Among survivors, the relationship between the $\%$ RFLV and the requirement for ECMO was also analyzed. The relationships between the \%RFLV and the duration of ventilator care, as well as the requirement for oxygen therapy were investigated.

Data were presented as medians (ranges). Statistical analysis of continuous and categorical variables was conducted with the Mann-Whitney $U$ test and Fisher's exact test, respectively. $p$ Values were considered statistically significant at $<0.05$.

\section{RESULTS}

The overall survival rate was $61.9 \%$. The prenatal and neonatal characteristics are shown in Table 1 . There were no differences between nonsurvivors and survivors in the prenatal factors, except for threatened preterm labor. In addition, there were no differences between nonsurvivors and survivors in the neonatal factors, except in the use of INO.

The \%RFLV in nonsurvivors was significantly lower than in survivors $[18.5 \%(0.0-4.3)$ versus $53.4 \%$ (32.4-66.6), $p=$ 0.0014; Fig. 3]. The area under the ROC curve for the sensitivity and specificity of various ratio cutoffs for predicting postnatal mortality was 0.90 (Fig. 4). The best cutoff was the value of $45 \%$ of the ERFLV. This value had a sensitivity 
Table 1. Prenatal/neonatal characteristics of the study population

\begin{tabular}{|c|c|c|c|c|}
\hline & Overall $(n=21)$ & Nonsurvivors $(n=8)$ & Survivors $(n=13)$ & $p$ \\
\hline Maternal age (y) & $29(18-37)$ & $27(18-36)$ & $29(19-37)$ & 0.2257 \\
\hline GA at diagnosis (wk) & $29(19-37)$ & $26(19-33)$ & $31(22-37)$ & 0.1364 \\
\hline GA at MRI (wk) & $34.7(25.9-37.9)$ & $32.9(25.9-37.6)$ & $31(22-37)$ & 0.1475 \\
\hline Preterm labor & $6(26 \%)$ & $5(63 \%)$ & $1(8 \%)$ & 0.0139 \\
\hline GA at birth (wk) & $37.9(37.1-39.7)$ & $37.9(37.3-38.9)$ & $37.7(37.1-39.7)$ & 0.7151 \\
\hline Cesarean section & $16(76 \%)$ & $7(88 \%)$ & $9(69 \%)$ & 0.6065 \\
\hline Apgar score $(1 \mathrm{~min})$ & $2(1-5)$ & $2(1-5)$ & $3(2-5)$ & 0.2626 \\
\hline Apgar score (5 min) & $3(2-10)$ & $3(2-5)$ & $3(2-10)$ & 0.2522 \\
\hline INO & $15(71 \%)$ & $8(100 \%)$ & $7(54 \%)$ & 0.0456 \\
\hline ECMO & $7(33 \%)$ & $2(25 \%)$ & $5(38 \%)$ & 0.6557 \\
\hline
\end{tabular}

of 1.00 and a specificity of 0.69 for predicting mortality. The PPV and NPV were 0.67 and 1.00 , respectively (Table 2 ). The pulmonary baseline presented completely in $3(38 \%)$ and 13 $(100 \%)$ of the nonsurvivors and survivors, respectively ( $p=$ $0.028)$. For predicting postnatal mortality, the sensitivity and

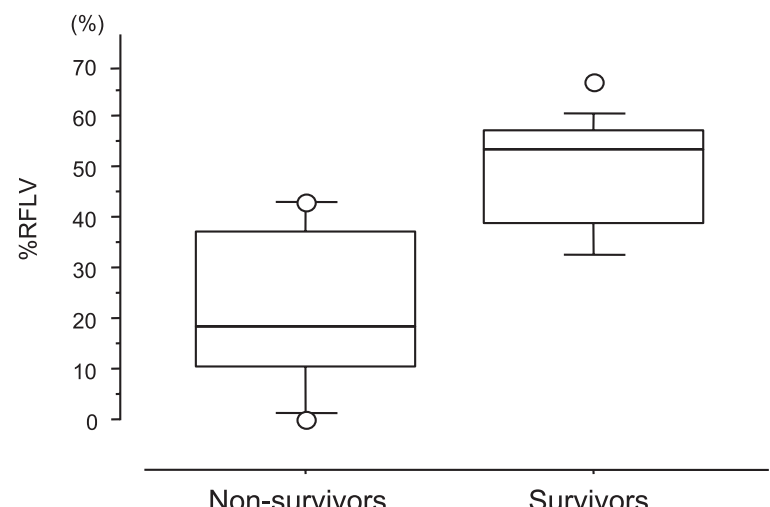

Figure 3. The comparison of the \%RLV between nonsurvivors and survivors. The horizontal bar within the box corresponds to the median. The upper and lower bars of the boxes correspond to the first and third quartiles, respectively. The upper and lower whiskers represent the 90th and 10th percentiles, respectively. The observations with an open circle were considered extreme outliers.

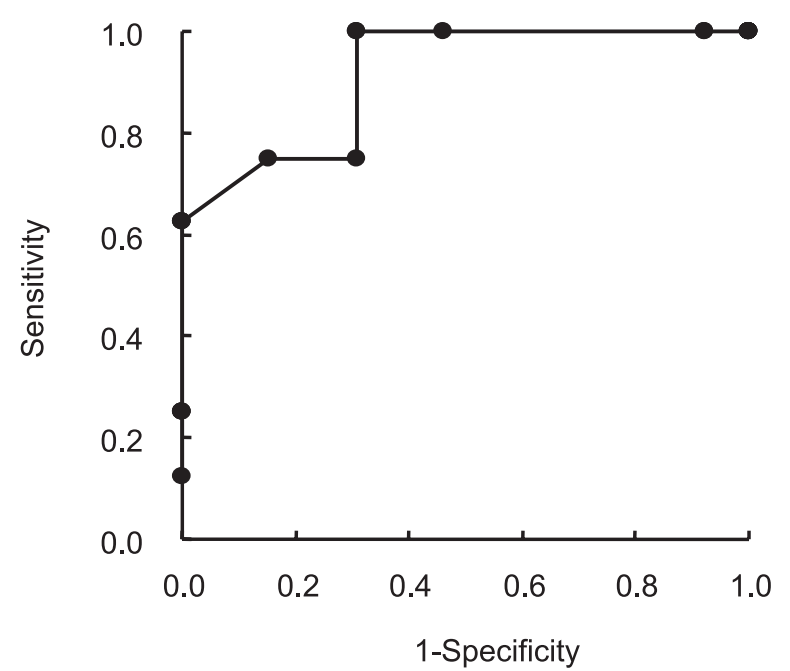

Figure 4. Receiver operator characteristic curve showing performance of various fetal lung volume ratio cutoffs for discriminating between survivors $(n=13)$ and nonsurvivors $(n=8)$. The area under the curve is 0.90 . the specificity were 0.63 and 1.00 , respectively. The PPV and NPV were 1.00 and 0.81 , respectively.

Among the survivors, the \%RFLV of the infants treated with ECMO was significantly lower than that of the infants treated without ECMO [38.9\% (32.4-51.1) versus $55.8 \%$ (38.4-66.6), $p=0.0127]$. The best threshold of the \%RFLV for predicting a requirement for ECMO was $50.0 \%$. The sensitivity and specificity were 0.80 and 0.88 , respectively. The PPV and NPV were 0.80 and 0.88 , respectively.

The duration for which oxygen therapy was required significantly correlated with the \%RFVL (oxygen requirement duration $=-1.08 \times \% \mathrm{RFLV}+84.9 ; \mathrm{R}^{2}=0.334, p=0.023$ ) (Fig. 5). The relationship between the \%RFLV and the duration of ventilator care, however, did not reach statistical significance (duration of ventilator care $=-0.33 \times$ $\%$ RFLV + 38.7; $\mathrm{R}^{2}=0.086, p=0.30$ ) (Fig. 6).

Table 2. The relationship between fetal MRI findings and postnatal mortality

\begin{tabular}{|c|c|c|c|c|c|c|}
\hline & Nonsurvivors & Survivors & Sensitivity & Specificity & PPV & NPV \\
\hline \multicolumn{7}{|l|}{$\%$ RFLV } \\
\hline$<45 \%$ & 8 & 4 & 1.00 & 0.69 & 0.67 & 1.00 \\
\hline$\geq 45 \%$ & 0 & 9 & & & & \\
\hline \multicolumn{7}{|l|}{$\begin{array}{l}\text { Pulmonary } \\
\text { baseline }\end{array}$} \\
\hline Incomplete & 5 & 0 & 0.63 & 1.00 & 1.00 & 0.81 \\
\hline Complete & 3 & 13 & & & & \\
\hline
\end{tabular}

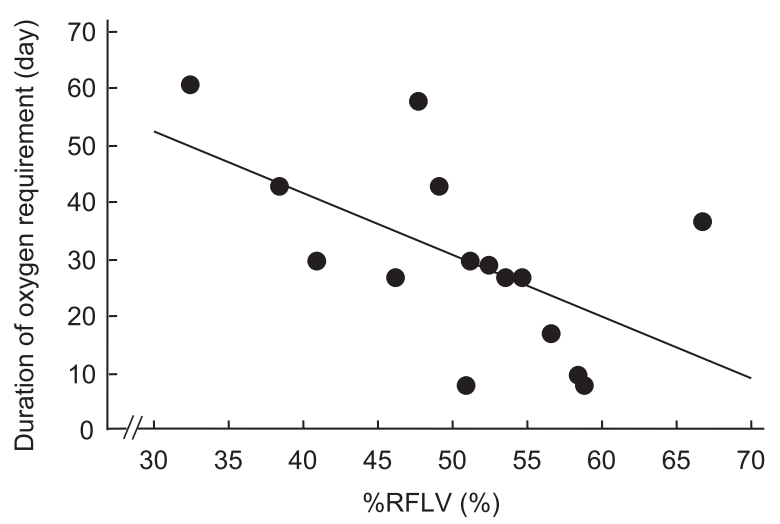

Figure 5. Relationship between the \%RLV and the oxygen requirement duration. The oxygen requirement duration was significantly correlated with the \%RFLV. Oxygen requirement duration $=-1.08 \times \% \mathrm{RFLV}+84.9\left(\mathrm{R}^{2}=\right.$ $0.334, p=0.023$ ). 


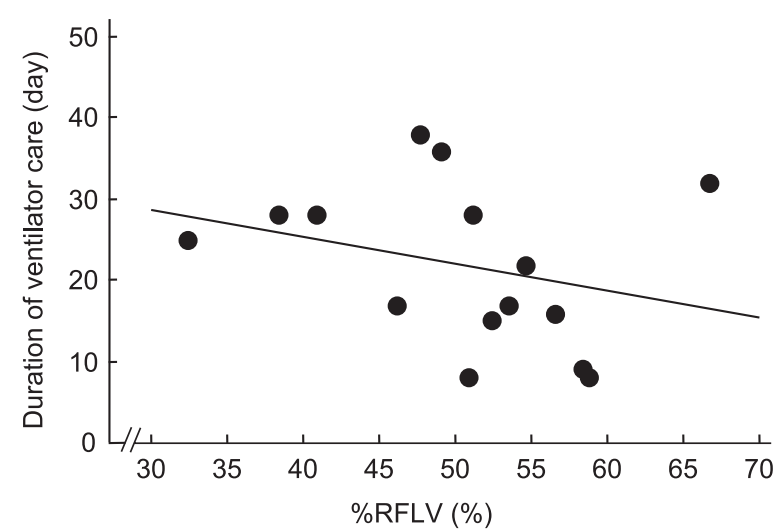

Figure 6. Relationship between the \%RFV and the duration of ventilator care. The duration of ventilator care was not significantly correlated with the $\%$ RFLV. The duration of ventilator care $=-0.33 \times \%$ RFLV $+38.7\left(\mathrm{R}^{2}=\right.$ $0.086, p=0.30)$.

\section{DISCUSSION}

In this study, we demonstrate that the \%RFV is a predictor of both mortality and a requirement for ECMO. When a cutoff of $45 \%$ was used, the \%RFLV predicted mortality with a sensitivity and specificity of 1.00 and 0.69 , respectively, and a PPV and NPV of 0.67 and 1.00, respectively. An incomplete pulmonary baseline was also a good predictor of postnatal mortality in prenatally diagnosed $\mathrm{CDH}$. The sensitivity and specificity of this finding were 0.63 and 1.00 , respectively. The combination of the shape of the right-sided pulmonary baseline and the \%RFLV on fetal MRI might be able to predict postnatal mortality with a high value for both sensitivity and specificity. Additionally, the \%RFLV was well associated with the requirement for ECMO. Thus, MRI is a valuable imaging modality for prenatally diagnosing CHD.

The method used to estimate the FLV in this study was very important. In a study demonstrating a lack of association between FLV and survival (16), the FLV was divided by the gestational age to standardize the FLV for the gestational age. This standardization method may have obscured the difference between the survivors and the nonsurvivors. Additionally, previous studies that found that MRI was a good predictor of postnatal mortality evaluated the bilateral FLV/expected bilateral FLV ratio $(17,18)$. In this study, however, we were able to demonstrate a difference looking only at the contralateral lung, observing that a cutoff for the ERFLV of $45 \%$ yields the best sensitivity and specificity. This is somewhat higher than the cutoff of 30\% presented in another study (20). The higher cutoff in this study is likely because the contralateral FLV, rather than the bilateral FLV, was used for the calculations. Even though both the contralateral FLV/expected contralateral FLV ratio, as well as observed bilateral FLV/expected bilateral FLV ratio can predict mortality, we chose to restrict our analysis to the contralateral lung even when the ipsilateral lung could be clearly detected. This was done since the severity of hypoplasia of the contralateral lung plays a decisive role with regard to survival (21).

We investigated the relationship between \%RFLV and postnatal respiratory care, namely the duration for which supplementary oxygen and ventilator support were required. The
$\%$ RFVL significantly correlated with the length of time that oxygen was required, but not the length of time spent on a ventilator. We are unable to fully explain this phenomenon. It is possible that the amount of time on the ventilator is affected by other factors, including surgical complications such as chylothorax. Additionally, the number of infants in this study was small. Thus, a larger study is necessary to evaluate the relationship between the \%RFLV and postnatal respiratory care.

In this study, we also evaluated whether the right-sided pulmonary baseline could be completely visualized on fetal MRI, and how the presence of a complete baseline affected prognosis. An incomplete pulmonary baseline was more frequently recognized in nonsurvivors than in survivors. Compression of the pulmonary base might significantly reduce FLV given that human lungs are somewhat conical in shape. It is quite possible that an incomplete pulmonary baseline reflects compression, and is therefore a good predictor of pulmonary hypoplasia in fetuses with $\mathrm{CDH}$.

The obstetrical ultrasound has been used to predict postnatal survival in CDH. Parameters used in two-dimensional ultrasonography include the ratio of the lung to the transverse thoracic area $(22,23)$ and the ratio of the lung to the head $(24,25)$. The FLV can also be measured with threedimensional ultrasonography (26-28). Because ultrasonography can be performed at the bedside, this technique is widely used to evaluate $\mathrm{CDH}$ prenatally. Ultrasonography, however, does have some disadvantages. First, image resolution is sometimes limited by fetal position, maternal obesity, and oligohydramnios. Second, it is difficult to distinguish between fetal liver and fetal lung on ultrasound. In our study, the MRI images were of high resolution, with good definition of the fetal lung contours. MRI also overcomes artifacts due to fetal motion, because of the rapid scan time.

The prenatal evaluation of CDH has several advantages. First, parents may be counseled regarding prognosis, and may then make informed decisions regarding treatment. In this study, a \%RFLV of more than $45 \%$ predicted postnatal mortality with a sensitivity of 1.00 and a NPV of 1.00 . Additionally, an incomplete pulmonary baseline predicted postnatal mortality with a specificity of 1.00 and a PPV of 1.00 (Table 2). Therefore, when both the \%RFV of more than $45 \%$ and a complete right-sided pulmonary baseline are recognized, postnatal survival is almost completely assured. In contrast, when both the \%RFLV of $<45 \%$ and an incomplete presence of right-sided pulmonary baseline are recognized, fetal survival will be unlikely without treatment. The use and effect of treatments such as FETO are controversial (29-31); thus, it is prudent to reserve these interventions for fetuses unlikely to respond to more conventional treatments. Deprest et al. (30) evaluated the severity of $\mathrm{CDH}$ according to fetal lung-to-head ratio and suggested that FETO improved the survival rate in fetuses with severe $\mathrm{CDH}$. For the infants with a low degree of $\%$ RFLV, FETO might improve survival. Appropriate resuscitation immediately after birth improves the outcome in infants with prenatally diagnosed $\mathrm{CDH}$ (32). Predicting whether interventions such as INO and ECMO are needed will help pregnant women plan for delivery at a tertiary center prepared 
to resuscitate and immediately provide intensive care to the neonate. In contrast, aggressive resuscitation, such as intubation immediately after birth, may be unnecessary for infants with mild $\mathrm{CDH}$.

This study has several strengths. First, this is a prospective study performed at a single institution. Prenatal evaluation of the MRI enabled the raters to be blinded to postnatal outcome. Thus, there was no bias introduced from the evaluation of the fetal MRI. Lastly, we used uniform criteria for selecting cases. This study was not without a few limitations. First, two small for gestational age (SGA) infants were included, and the ERFLV in SGA infants might be underestimated. One SGA was a male infant born at 37.3 wk of gestation with a birth weight of $1926 \mathrm{~g}$. The other was a female born at $38.9 \mathrm{wk}$ of gestation with a birth weight of $2028 \mathrm{~g}$. Neither of the SGA infants suffered from the most severe form of growth retardation. Therefore, we do not believe that the infants' size significantly influenced the evaluation of \%RFL. We will be conducting an additional study to evaluate the relationship between ERFLV and expected fetal body weight. Another study limitation is the small number of fetal MRI scans evaluated. The mortality predictor and the formula of the normal FLV in our study are compatible with what has been previously reported (18). Thus, we believe our results are reliable even with a small sample size. Further large studies are needed to confirm our findings.

In conclusion, the \% RFLV and the shape of contralateral lung on fetal MRI can be useful in predicting the mortality of prenatally diagnosed $\mathrm{CDH}$. There was a strong association between the \%RFLV and the need for ECMO in the neonatal intensive care unit.

\section{REFERENCES}

1. Cannon C, Dildy GA, Ward R, Varner MW, Dudley DJ 1996 A population-based study of congenital diaphragmatic hernia in Utah: 1988-1994. Obstet Gynecol 87:959-963

2. Stege G, Fenton A, Jaffray B 2003 Nihilism in the 1990s: the true mortality of congenital diaphragmatic hernia. Pediatrics 112:532-535

3. Levison J, Halliday R, Holland AJ, Walker K, Williams G, Shi E, Badawi N 2006 A population-based study of congenital diaphragmatic hernia outcome in New South Wales and the Australian Capital Territory, Australia, 1992-2001. J Pediatr Surg 41:1049-1053

4. Colvin J, Bower C, Dickinson JE, Sokol J 2005 Outcomes of congenital diaphragmatic hernia: a population-based study in Western Australia. Pediatrics 116:e356e363

5. Frenckner B, Ehren H, Granholm T, Linden V, Palmer K 1997 Improved results in patients who have congenital diaphragmatic hernia using preoperative stabilization, extracorporeal membrane oxygenation, and delayed surgery. J Pediatr Surg 32:1185-1189

6. Cacciari A, Ruggeri G, Mordenti M, Ceccarelli PL, Baccarini E, Pigna A, Gentili A 2001 High-frequency oscillatory ventilation versus conventional mechanical ventilation in congenital diaphragmatic hernia. Eur J Pediatr Surg 11:3-7

7. Bohn D 2002 Congenital diaphragmatic hernia. Am J Respir Crit Care Med 166:911-915

8. Okuyama H, Kubota A, Oue T, Kuroda S, Ikegami R, Kamiyama M, Kitayama Y, Yagi M 2002 Inhaled nitric oxide with early surgery improves the outcome of antenatally diagnosed congenital diaphragmatic hernia. J Pediatr Surg 37:1188-1190

9. Downard CD, Jaksic T, Garza JJ, Dzakovic A, Nemes L, Jennings RW, Wilson JM 2003 Analysis of an improved survival rate for congenital diaphragmatic hernia. J Pediatr Surg 38:729-732
10. Mallik K, Rodgers BM, McGahren ED 1995 Congenital diaphragmatic hernia: experience in a single institution from 1978 through 1994. Ann Thorac Surg 60:1331-1336

11. Gallot D, Coste K, Francannet C, Laurichesse H, Boda C, Ughetto S, Vanlieferinghen P, Scheye T, Vendittelli F, Labbe A, Dechelotte PJ, Sapin V, Lemery D 2006 Antenatal detection and impact on outcome of congenital diaphragmatic hernia: a 12-year experience in Auvergne, France. Eur J Obstet Gynecol Reprod Biol 125:202-205

12. Molenaar JC, Bos AP, Hazebroek FW, Tibboel D 1991 Congenital diaphragmatic hernia, what defect? J Pediatr Surg 26:248-254

13. Adzick NS, Harrison MR, Glick PL, Nakayama DK, Manning FA, deLorimier AA 1985 Diaphragmatic hernia in the fetus: prenatal diagnosis and outcome in 94 cases. J Pediatr Surg 20:357-361

14. Dommergues M, Louis-Sylvestre C, Mandelbrot L, Oury JF, Herlicoviez M, Body G, Gamerre M, Dumez Y 1996 Congenital diaphragmatic hernia: can prenatal ultrasonography predict outcome? Am J Obstet Gynecol 174:1377-1381

15. Bootstaylor BS, Filly RA, Harrison MR, Adzick NS 1995 Prenatal sonographic predictors of liver herniation in congenital diaphragmatic hernia. J Ultrasound Med 14:515-520

16. Walsh DS, Hubbard AM, Olutoye OO, Howell LJ, Crombleholme TM, Flake AW, Johnson MP, Adzick NS 2000 Assessment of fetal lung volumes and liver herniation with magnetic resonance imaging in congenital diaphragmatic hernia. Am J Obstet Gynecol 183:1067-1069

17. Mahieu-Caputo D, Sonigo P, Dommergues M, Fournet JC, Thalabard JC, Abarca C Benachi A, Brunelle F, Dumez Y 2001 Fetal lung volume measurement by magnetic resonance imaging in congenital diaphragmatic hernia. BJOG 108:863-868

18. Gorincour G, Bouvenot J, Mourot MG, Sonigo P, Chaumoitre K, Garel C, Guibaud L, Rypens F, Avni F, Cassart M, Maugey-Laulom B, Bourliere-Najean B, Brunelle F, Durand C, Eurin D 2005 Prenatal prognosis of congenital diaphragmatic hernia using magnetic resonance imaging measurement of fetal lung volume. Ultrasound Obstet Gynecol 26:738-744

19. Moore TR, Cayle JE 1990 The amniotic fluid index in normal human pregnancy. Am J Obstet Gynecol 162:1168-1173

20. Bonfils M, Emeriaud G, Durand C, Brancato S, Nugues F, Jouk PS, Wroblewski I, Debillon T 2006 Fetal lung volume in congenital diaphragmatic hernia. Arch Dis Child Fetal Neonatal Ed 91:F363-F364

21. Bahlmann F, Merz E, Hallermann C, Stopfkuchen H, Kramer W, Hofmann M 1999 Congenital diaphragmatic hernia: ultrasonic measurement of fetal lungs to predict pulmonary hypoplasia. Ultrasound Obstet Gynecol 14:162-168

22. Hasegawa T, Kamata S, Imura K, Ishikawa S, Okuyama H, Okada A, Chiba Y 1990 Use of lung-thorax transverse area ratio in the antenatal evaluation of lung hypoplasia in congenital diaphragmatic hernia. J Clin Ultrasound 18:705-709

23. Nakata M, Sase M, Anno K, Sumie M, Hasegawa K, Nakamura Y, Kato H 2003 Prenatal sonographic chest and lung measurements for predicting severe pulmonary hypoplasia in left-sided congenital diaphragmatic hernia. Early Hum Dev 72:75-81

24. Jani J, Keller RL, Benachi A, Nicolaides KH, Favre R, Gratacos E, Laudy J, Eisenberg V, Eggink A, Vaast P, Deprest J 2006 Prenatal prediction of survival in isolated left-sided diaphragmatic hernia. Ultrasound Obstet Gynecol 27:18-22

25. Laudy JA, Van Gucht M, Van Dooren MF, Wladimiroff JW, Tibboel D 2003 Congenital diaphragmatic hernia: an evaluation of the prognostic value of the lung-to-head ratio and other prenatal parameters. Prenat Diagn 23:634-639

26. Ruano R, Joubin L, Sonigo P, Benachi A, Aubry MC, Thalabard JC, Brunelle F, Dumez Y, Dommergues M 2004 Fetal lung volume estimated by 3-dimensional ultrasonography and magnetic resonance imaging in cases with isolated congenital diaphragmatic hernia. J Ultrasound Med 23:353-358

27. Peralta CF, Jani J, Cos T, Nicolaides KH, Deprest J 2006 Left and right lung volumes in fetuses with diaphragmatic hernia. Ultrasound Obstet Gynecol 27:551554

28. Ruano R, Benachi A, Joubin L, Aubry MC, Thalabard JC, Dumez Y, Dommergues M 2004 Three-dimensional ultrasonographic assessment of fetal lung volume as prognostic factor in isolated congenital diaphragmatic hernia. BJOG 111:423-429

29. Harrison MR, Keller RL, Hawgood SB, Kitterman JA, Sandberg PL, Farmer DL, Lee H, Filly RA, Farrell JA, Albanese CT 2003 A randomized trial of fetal endoscopic tracheal occlusion for severe fetal congenital diaphragmatic hernia N Engl J Med 349:1916-1924

30. Deprest J, Gratacos E, Nicolaides KH 2004 Fetoscopic tracheal occlusion (FETO) for severe congenital diaphragmatic hernia: evolution of a technique and preliminary results. Ultrasound Obstet Gynecol 24:121-126

31. Deprest J, Jani J, Van Schoubroeck, D Cannie M, Gallot D, Dymarkowski S, Fryns JP, Naulaers G, Gratacos E, Nicolaides K 2006 Current consequences of prenatal diagnosis of congenital diaphragmatic hernia. J Pediatr Surg 41:423-430

32. Betremieux P, Gaillot T, de la Pintiere A, Beuchee A, Pasquier L, Habonimana E, Le Bouar G, Branger B, Milon J, Fremond B, Wodey E, Odent S, Poulain P, Pladys P 2004 Congenital diaphragmatic hernia: prenatal diagnosis permits immediate intensive care with high survival rate in isolated cases. A population-based study. Prenat Diagn 24:487-493 